PROBLEMS

OF MANAGEMENT

IN THE $21^{\text {st }}$ CENTURY

Vol. 12 , No. 1,2017

20

\section{ACTIVITY THEORY APPLIED AT CHANNEL EXPANSIONS IN SMALL AND MEDIUM ENTERPRISES}

Siw Lundqvist, Leif Marcusson, John Jeansson

Linnaeus University, Sweden

E-mail: siw.lundqvist@Inu.se, leif.marcusson@Inu.se, john.jeansson@Inu.se

\begin{abstract}
Today's commonly carried out channel expansions of commerce could be both costly and problematic to manage. Especially for small and medium-sized enterprises (SMEs) that often suffer from a lack of digital competence, time and monetary resources in generally. Still, these transitions would be necessary to carry out because of customer demands and expectations concerning 24/7 availability, and access to digital commerce alternatives. Scarce resources are important reasons to search for how to carry out channel expansions with minimized problems. Activity theory (AT) focuses on the whole in order to detect problems that hinder successful outcomes. Hence, this theory was applied to prior findings, from a project about SME's channel expansions, highlighting several problems that could appear during these activities. Implications for research foremost involve issues connected to the use of AT; implications for practice particularly concern if and how AT could be used to support channel broadening activities.

Keywords: channel expansion, channel transition, digital commerce, "expansive visibilization of work method” (Sic! Engeströms' expression), multichannel, omni-channel, small and medium-sized enterprise (SME).
\end{abstract}

\title{
Introduction
}

Today's customers expect smooth, problem-free availability, and access to digital commerce alternatives twenty-four-seven (24/7). Businesses that do not manage to meet these customer demands risk to be outrun by others that succeed in living up to those expectations. E-commerce expert Müller (2016) states that despite the very fast pace of development of e-commerce, which is obvious for most people today, the pace of digital development is never going to be as slow as it is today. Hence, the companies that want to remain in business are forced to make extra effort to keep up with their competitors.

To carry out a channel expansion in order to meet up with customer expectations requires a lot of effort. Besides the monetary issues, which are often underestimated, and lack competence and skills, there are also factors on the human side that could be even more difficult to deal with. These human factors could partly be harder to anticipate, partly they could be more problematic to solve. Most people are inherently sceptical toward changes, and want to avoid them the best they can. On the one hand, it could be scary to have to deal with new competence requirements; on the other hand there could be stressful uncertainty about new positions. In any case, management needs to communicate imminent changes in a way that is easy to understand, and should also acknowledge possible feelings of apprehensions since manifestations of resistance could be a way of dealing with change (Lewis, Romanaggi, \& Chapple, 2010). Channel expansions are most likely to convey digitalization, which will need specific competence that in turn will require learning. Learning could be looked upon both as an opportunity and as a challenge. For SMEs (small and medium enterprises), and especially 
regarding micro companies, the resources must be utterly well utilized; something that could be facilitated by increased knowledge about possible contractions / hinders, which in turn conveys that the whole, including the context, needs to be scrutinized. For making a success of such an assignment, it could be an opportunity to try out using activity theory (henceforth AT), and Engeström's (e.g. 1999a, 1999b, 2000) "expansive visibilization of work method" in particular. It should be noted that Engeström minted the expression "visibilization" for this method, which is why it will be used henceforth without any adjusting according to linguistic reasons.

Swedish commerce consists of both chains and free stores, and it is common that the chain free stores are small. The conception of SME is defined by European Commission (2016):

- A small company exists of two sizes:

- A micro company is up to 10 employees and 2-million-euro turnover or balance sheet total.

- A small company is from 11 up to 49 employees and 10-million-euro turnover or balance sheet total.

- A medium company is from 50 up to 249 employees and 50-million-euro turnover or 43-million-euro balance sheet total.

Given that a channel expansion may be difficult for SMEs, it would be an advantage for business' to have access to supporting theories. By testing with data from several business' that have made expansion, it is possible to see if AT could be such a theory.

\section{Purpose and Research Question}

The purpose with this research was to test how AT could be used, and the more precise objective was to consider if "the expansive visibilization of work method" was applicable in a way that could facilitate channel broadening activities. It should be noticed though that this research did not aim at finding solutions to the problems that could be visualized by applying the method that Engeström (e.g. 1999a, 1999b, 2000) developed.

Because of AT's aiming at bringing the whole (e.g. Engeström 2005, 2008), including the context of an activity, to the analysis, it could be of interest to use its theoretical structure for detecting possible contradictions in activities connected to channel expansions. Such analyses should start with finding out, which opportunities there are for applying the AT structure to those transition activities. The research question is: How can businesses, that are about to engage in channel broadening activities, gain from applying AT, and particularly "the expansive visibilization of work method"?

\section{Theoretical Framework}

\section{A Brief Historical View of AT}

AT has its roots in psychology, in the former USSR, and was initially developed by the Russian researchers Vygotsky, Leont'ev and Luria (Engeström, 2005). According to Engeström (ibid.) AT ideas could be followed as far as to the German philosophy (Kant - Hegel) and also partly found in Marx and Engels' writings that elaborated on the concepts of activity; sometimes AT is called the cultural-historical activity theory (CHAT) (Fjeld, Lauche, Bichsel, Voorhorst, Krueger, \& Rauterberg, 2002; Foot, 2001).

Russian researcher Mironenko (2013) criticized that not all versions of early AT structures are given equally attention. Mironenko (ibid.) argued that Leont'ev's work was more focused than for example Vygotsky's and Rubinstein's versions of AT, which she argues as being problematic, even though Leont'ev also contributed a lot to the theory. According to Mironenko (ibid.), the reason for the unequal focusing of these theories is likely due to 'the political context of the development of science in a totalitarian state' (p. 392). Engeström (1999a) also problematized the fact that Leont'ev's version of AT did not actually change (not 
PROBLEMS

OF MANAGEMENT IN THE $21^{\text {st }}$ CENTURY Vol. 12, No. 1, 2017

22

in a graphically manner) the first generation's AT structure (i.e. Vygotsky's) even though the activity conception implied a big change regarding complexity grounded on interrelations concerning individuals and their community. In the Soviet Union this was quite a delicate issue, particularly concerning possible contradictions in general at this time, which conveyed that Vygotsky's unfavourable, critical thoughts were suppressed due to political reasons (ibid.).

The theory aims at paying attention to the whole and could therefore be described as more of a descriptive framework, or even a meta-theory, than a solely predictive one. The context is strongly taken into consideration, and the context is so to say built-in in the activity. AT is regarded as particularly helpful when it comes to gaining a better understanding of the everyday activities. The attention is not only focused on the object (as in objective / motive / goal that could be an entity, material or immaterial with the ability to transform into a result), or not solely on the subject either for that matter, instead it constitutes that an action must have both a subject (an actor) and an object as well as a mediating tool, and all three of these are highlighted as important. A tool in an AT structure should not be seen just as a technical device, and could just as well be something more conceptual like a model, a language or a method. For example, a physician, who needs access to a specific patient record, when examining the patient in question, reads the information on a computer screen. In that case it is not the computer that is the tool; instead it is the information that for the time being is made available by the computer. Only if computer problems occur, that hinder the physician to read the necessary information, is the computer as such of any interest as a mediating tool (Engeström, 2000).

In the mid-1980s AT was also applied in Scandinavia when the Finnish researcher Engeström further developed (i.e. extended) this theory, which also included development of the prior graphical structure (2005). Leont'ev had described some changes to Vygotsky's theory but did not add these changes (that distinguished between actions and activities) to the structure graphically. According to Engeström (1999a) there are three generations of AT that should be acknowledged:

- The first generation started with Vygotsky's idea of mediation, which was visible in the AT triad consisting of subject, object and mediating artefact (i.e. the context was highlighted as necessary for understanding of individuals and society via human artefacts),

- the second generation; inspired by Leont'ev's research, concerning the problem with the unit of analysis, which was regarded as too individually focused (i.e. there is a big difference between the individual's action and the collective's activity),

- $\quad$ and the third generation, which is Engeström's extended version (e.g. described in Engeström, 2005). Engeström's adding of: (a) community (to share the same object with the subject), (b) division of labour (to mediate between object and community), and (c) rules / norms (to mediate between subject and community) (cf. figure 1), to the prior versions of the AT structure. The latter has proved to be especially helpful when it comes to gain an understanding of complex work and social activities.

\section{Fundamental Principles of the AT Structure}

The parts in Figure 1 could be generally described as follows. The subject is an individual or a sub-group whose perspective is the one that is chosen as the perspective of the activity analysis (Engeström \& Sannino, 2010). The object carries the motive of the activity (i.e. futureoriented purpose of the activity). AT is an object-oriented theory, and therefore the motivation for carrying out activities is found in the objects (and not in the subjects). 'The object is turned into outcomes with the help of instruments, that is, tools and signs.' (Ibid., p. 6) Hence, instruments (tools, signs) are mediating between the subject and the object. The community comprises those (i.e. individuals or sub-groups), who share object with the subject and mediates between subject and object from yet another perspective (compared to instruments). The division of labour is 
about those, who are actually mediating between community and object (i.e. could have been nurses helping a specialist with patient tests). In any case, they will be mentioned when they have a role to play in the structure, which is to say that they are of importance for the analysis of the activity (Engeström, 2000). Rules are mediating between subject and community and could for example involve policies and norms (Allen, Karanasios, \& Slavova, 2011). However, if rules, community or division of labour are not directly involved in a particular activity, they do not need to be depicted in the structure of that particular activity structure (Engeström, 2000). There is not any contradictions illustrated in this structure (figure 1) - when contradictions appear they are depicted by a flash of lightning in the structure. The outcome is what the activity aims at, i.e. the reason for finding the contradictions that are often causing problems, so they should not hinder the activity to be successfully turned into the desired outcome. It should be noticed though, that the object of activity could be a moving target that begins merely as a 'raw material' (Engeström, 2001, p. 136) and further to 'a collectively meaningful object constructed by the activity system' and then to 'jointly constructed object'.

\section{Instruments:}

\section{Medical knowledge}

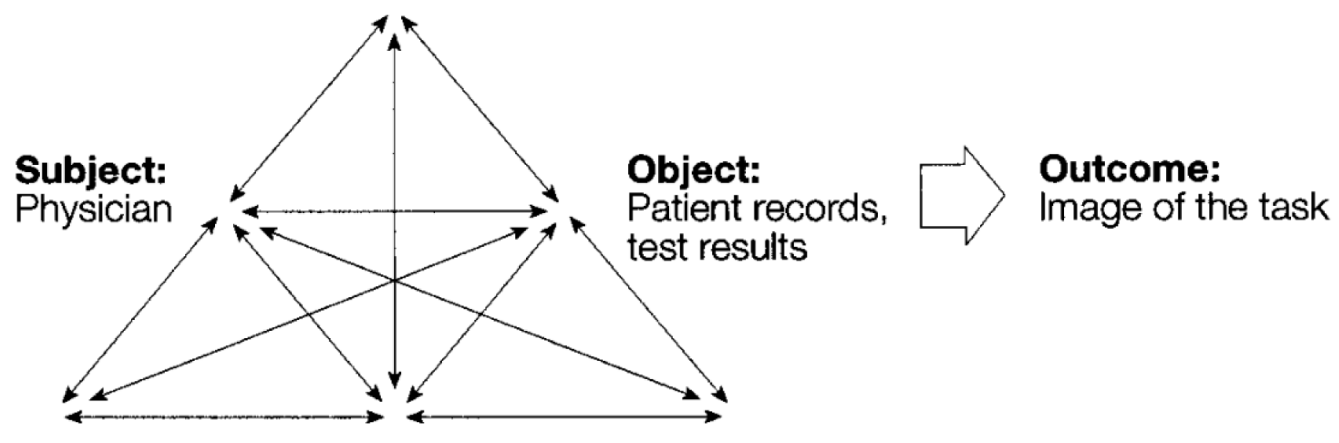

\section{Rules Community Division of Labour} Figure 1: An activity example from a hospital study, showing an extended AT
structure (Engeström, 2000, p. 962).

Engeström (2008) proposed the necessity to further explore the unit that mediates between activity and action. Engagement and working spheres are suggested as possible candidates; still critical questions connected to the consequences must also be scrutinized. According to Engeström (2008) AT is an open theory that preferably should be enriched continually 'but the enrichment has to take place without shortcuts' (ibid. p. 259), e.g. it could be too easy to add yet another level to the AT structure according to Engeström (ibid.), who have seen such examples. Activity systems are changing continuously causing various contradictions meanwhile (Engeström, 2000). The framework of AT was found suitable for analysing and redesigning work, and for example are the features that allow the users to distinguish between 'short-lived, goal-directed actions and durable, object-oriented activity systems' considered to be suitable for these purposes (ibid., p. 960). Further, this framework addresses the dichotomies between micro / macro, mental / material, quantitative / qualitative and, observation / intervention in a sufficient way (ibid). There are five principles of AT that are intended to summarize AT: (a) the activity system as the unit of analysis (AT is a theory that take a standpoint in activities), (b) multivoicedness (built-in in the structure because of different participants' history, points of view and various different perspectives), (c) historicity (the history is necessary in order to fully understand the activity system), (d) contradictions (tensions indicating problems, aiming at change and development), and (e) expansive cycles (the possibility of expansive transformations with a starting point in contradictions) (Engeström, 2001). 
PROBLEMS

OF MANAGEMENT

IN THE $21^{\text {st }}$ CENTURY

Vol. 12, No. 1,2017

\section{AT and Digitalization}

Today's ongoing digitalization conveys attention to various technical issues that are connected to this inevitable societal development (Fujitsu, 2016). Hence, a search for appropriate theories and methods that could facilitate the necessary transitions would most likely be very useful. An example of such transition is channel expansions of commerce (Jeansson, Nikou, Lundqvist, Marcusson, Sell, \& Walden, 2017). Allen et al. (2011) demonstrated the usefulness of applying CHAT to studies about information behaviour because of the framework, the semantic tools, and the hierarchy of activity, action and operation that is provided. Actions, activities, and operations are distinguished from each other and given different meaning. Foot (2001) described the distinctive character of these three from yet another important perspective, i.e. concerning whether the actions are conscious or unconscious. For example, people who have never before used either computers or email systems, have to overcome some serious struggling before they learn how to send and receive emails. The learning process will in that case require both conscious and tool-mediated actions, but 'with practice, sending email becomes an operation comprised of actions that have become automatic, thus condensed and unconscious' (ibid., p. 60). Uden and Willis (2001) expressed hopefulness about the possibilities to use AT for designing user interface since the human side is incorporated in the design. Fjeld et al. (2002) propagated the usability of AT for designing and developing groupware, Engeström (2005, p. 159) argued that 'activity theory has an original and potentially powerful approach to the social construction of knowledge', and Foot (ibid.) proposes that CHAT is an approach that is especially suitable for studying virtual groups.

Karanasios, Allen, and Finnegan (2015) formulated a call for papers (on behalf of the Information Systems Journal) focusing on the role that AT plays in Information systems (IS) research. AT is considered particularly well suited for carrying out IS research because it does not prioritize technology above human, nor does it prioritize human over technology, instead it takes a socio-technical perspective. Hence, it is regarded as especially interesting to highlight AT's contribution to IS research. Rückgriem (2010) put the light on the fact that neither Vygotsky (particularly not), nor Leont'ev actually lived to experience the big expansion of digital technology, and therefore neither of them were suited to reflect on what the digitalization of society would bring on. Still, digitalization is regarded as highly important since digital devices are common means for mediation nowadays (ibid.). AT's adequacy in the light of the contemporary technology advances and opportunities should be further tested. Perhaps it could be helpful to apply AT to research in the fields of digital commerce and channel expansions. Engeström (1999a, 1999b) developed a method for "expansive visibilization of work", which is about the movement from actions to activity and back (e.g. p. 69). As regards manifestation of contradictions, these show how changes due to disturbances and small innovations in everyday work actions will lead to changes.

\section{A Short Description of the "Expansive Visibilization of Work Method"}

Engeström (e.g. 1999a, 1999b, 2000) further developed (his own) method called "expansive visibilization of work" that is directed towards organizational, and work, development through learning. The background for development of this method emerged from other methods' ability (or rather disability) to not only show work as a linear flow from one task to another but also to include a socio-spatial dimension of work like the ethnographers do. Business process reengineering (BPR) (e.g. Hammer \& Champy, 1993) is an example of work described as a linear flow even though external and internal performance, in the perspective of optimization, is included. There is still nothing about new alternatives i.e. customers, products, and tasks. Because of AT's concentration on distinguishing between the individual goal-directed actions and the collective (and object-oriented) activity, the historicity is important. Actions, no matter if they are linear or socio-spatial, are proportionately short, compared to activities, and 
that is why they, from a developmental perspective, must be seen in a historical context in order to be correctly understood. According to Engeström (1999a, p. 65) 'Thus, the developmental dimension can only be grasped when the unit of analysis is expanded to the collective activity system'. However, Engeström (2008) also warned for the risk to choose short-cuts when it comes to attempts to further development or enrichment of AT.

In a clinical work-study Engeström (1999b) employed three dimensions that represent work: (a) linear, (b) socio-spatial, and (c) developmental. These three dimensions were helpful in order to expand the patient from being the object of clinical work to an expanded object (with a new motive) and a developmental dimension of work (ibid.). The process made various problems visible (i.e. showed contradictions) which led to development of new routines, arising from these contradictions, that finally resulted in a shared patient record that both patient (and family), and several care professional gained a lot from (Engeström, 1999b). The contradictions should not primarily be seen as problems but as opportunities to solve these, and they should point to solutions to the problems that have been visualized through analysis of the AT structures. Changes and revisions of an actual activity should be elaborated on back and forth in order to find the best solution (which also is something that would change as time passes). The area in which these revisions are carried out is called 'the zone of proximal development' (ibid., p. 69), and it is actually all about trying new actions in several versions with the objective to solve disturbances. Just like what happened with the contradictions that appeared in the hospitalstudy and that were solved by the routine changes. Further, Engeström and Kerosuo (2007) advocated the need for bringing AT into organizational and work place research even though some argue that this would risk focusing mostly on the collective' systems and structures while the individual is forgotten. However, according to Engeström and Kerosuo (ibid.) it is rather the other way around since interventions in research settings must involve the individuals and 'organization must necessarily be translated back into a workplace inhabited by human beings' (p. 340). Today, the theory of expansive learning represents the further developed "expansive visibilization", and it is "a powerful framework with which practitioners and researchers may collectively question their everyday practices, find new ways of acting in their organizations and manage contradictions in their activity systems" (Engeström \& Scaratti, 2016, p. 170). Furthermore, change laboratory is a formative intervention about organizational change in "a longitudinal and dialectical process driven by contradictions" (Sannino, Engeström, \& Lahikainen, 2016, p. 247). The interventions can be about transformational or incremental change combined with implementation or formation (Virkkunen \& Newnham, 2013). The change laboratory contains (a) model and vision, (b) ideas and tools, and (c) mirror. These three are described in three time aspects: past, present, and future.

Engeström and Sannino (2010) propagated the necessity of using the theory of expansive learning for today's and tomorrows 'pressing issues' (p. 21). This theory was proposed to be suitable for usage because of its possibilities to analyse several directions that covers both collective activity systems (both shared and contested objects), and subjective issues (e.g. actions). Still, to succeed in applying expansive learning would require serious efforts both theoretically and empirically (ibid.). As regards this research is should be seen as a test of the possibilities to use AT for channel broadening, which in this case is carried out after the actual work with channel broadening was completed. If this test turns out positive, it is strongly advisable though to use the latest developed method, i.e. change laboratory, for future work with channel broadening.

\section{The Four Steps of "Expansive Visibilization"}

"The expansive visibilization of work method" consists of four steps for "visibilization" (Engeström 1999a, 1999b): (a) mirroring and analysing troublesome actions, (b) modelling activity systems, (c) designing and implementing new actions, and (d) following and revising; these steps will be further described. Starting with the first step that mirrors and analyses 
PROBLEMS

OF MANAGEMENT

IN THE $21^{\text {st }}$ CENTURY Vol. 12 , No. 1, 2017

26

problems / troublesome actions, points out the necessity of gaining enough knowledge and inside information to be able to work further with, and analyse these actions. Engeström (1999b) described the initial work process in which samples of various disturbances should be collected. This could be carried out by for example using interviews as well as videotaping and/ or observing those that are involved in the activities of immediate interest (i.e. the practitioners).

The second step is about modelling activity systems and builds upon the information of disturbances from the first step. In the first step, these were observed but not further scrutinized. The second, modelling step also requires participation from those that are involved in the activities. They will for example be asked to reveal their opinion of the worst-case scenario that could happen due to the contradictions. In order to start the analysis, a historical analysis of how the activity systems have developed would be required that will lead to 'a first approximation of the inner contradictions of the activity system' (Engeström, 1999b, p. 77) so that important tensions could be identified and discussed, and placed in the activity system. Both present and future suggested activity systems should be depicted, and these would be the basis for creating of the new activity that should be based on its object and the motive of the activity (not the goals of the actions as such).

The third step is about designing and implementing new actions, and sets out from the activity systems that were suggested in step two. Practitioners that were involved in the actions, that were pointed out earlier as troublesome, work in so called task force groups in order to formulate proposals for how these actions can be redesigned. In this phase the work is presented in a linear flow that identifies a string of actions that will show both the present and the redesigned process/-es.

The fourth step is to follow up and to analyse how the redesigned processes work as well as to carry out revisions that were considered as necessary. Engeström (1999b) stated that 'coherent analytical explanation and goal-setting may come only after the creation and practical implementation of innovative solutions' (p. 63), which emphasizes the importance of working in an iterative way with the activity structures.

\section{Methodology of Research}

\section{Sample of Research}

The research about channel expansion has been carried out with the participation of representatives from $18 \mathrm{SME}$ companies in Sweden during 2014. The research was carried out by interviewing executives of retail enterprises with the aim to grasp a holistic understanding of the phenomenon from the interviewees' point of view; the method could nearest be categorized as a basic qualitative research approach (Merriam, 2009). The reason behind interviewing executives was that they from their leading positions have insight and knowledge that made them well suited for delivering relevant and initiated answers to the interview questions. There were some official documents, including the retailers' websites, that were collected and those were useful as background material when the interview guide was prepared.

\section{Instrument and Procedures}

Criteria that the interviewees should meet was that they should belong to the SME category, have been involved in one or more channel expansions (the latest of these was focused during the interview, table 1), be vendor of products and/or services to consumers and should operate on the Swedish market. Table 1 shows how many companies from each enterprise size that was participating, and their latest transition. 
Table 1. Participating companies.

\begin{tabular}{lllll}
\hline \multirow{2}{*}{ Enterprise size } & \multicolumn{2}{l}{ The latest carried out transition was to: } & \multirow{2}{*}{ Sum } \\
\cline { 2 - 5 } & Physical store & e-commerce & m-commerce & 11 \\
\hline Micro & 2 & 5 & 4 & 4 \\
\hline Small (excl. micro) & 1 & 3 & 0 & 3 \\
\hline Medium & 0 & 2 & 1 & 18 \\
\hline Total & 3 & 10 & 5 & \\
\hline
\end{tabular}

Eleven of the participating companies were categorized as micro companies, four as small companies (micro excluded), and three as medium sized companies; they represented trading / retail and service businesses. The interviews were semi-structured and lasted for approximately between 60 to 90 minutes; 16 interviews were carried through at the retailers head offices, and two were carried out as a telephone interview since that was the only alternative in those cases. The interviews were recorded and literally transcribed.

Because interview procedures were applied, ethical aspects must be carefully attended to. The interviewees were promised confidentiality, including that their companies should not be mentioned by name, neither should they be described on a detailed level that could risk the confidentiality. The participants, and their companies, should not be recognized. Further, during some of the interviews, an interviewee could suddenly point out that certain issues that they just had mentioned should be handled with secrecy. This happened a few times, and in order to fulfil promises about confidentiality, such information was excluded from the transcripts. The interviewers asked the interviewees specifically for permission to use quotations, those were affirmatively answered in advance; only a few added that in case they were quoted they wanted to read and accept before publishing. Due to how the ethical issues were taken care of, and the fact that no sensitive data were used, the research (i.e. the eTransit project, e.g. Jeansson et. al., 2017) did not even need to apply for permission from the central ethical review board.

\section{Data Analysis}

Collected data were analysed with perspectives of AT, and its fundamental principles. Categories were constructed (cf. table 2, Results of Research section) which is part of step one of "the expansive visibilization of work method". The three remaining steps of "the expansive visibilization of work method" were applied, one at the time.

The data were collected after the transitions were carried out. The first step of Engeström's (e.g. 1999b) method conveyed a coding that made it possible to categorize and analyse developmental tensions (cf. figure 2). These tensions provided input to step two of the method that after further analysis revealed possible problem areas (cf. figure 3 ). The two most explicit problem areas were chosen for further analysis; a new coding was carried out regarding technical problems and a lack of competences. These problem areas provided, after analysis, input to step three that handled designing and implementing of new actions. In order to fulfil step three new coding sessions of the transcripted data were carried out in search for the solutions of these problem areas. A new round of analysis followed, and led to AT structures dealing with one problem area at the time (cf. figures $4 \& 5$ ), including how these problems were attended to. The fourth step, which is a follow-up and an evaluation about how the problems were solved (cf. figure 6) should include an assessment of both positive and negative consequences of the measures taken, was in this research fulfilled by yet an analysis of data from the interviews. This research builds on data that were collected after the channel expansions actually had been carried out (e.g. Jansson et al., 2017). Hence, it was not possible for the researchers to be involved in the specific channel broadening activities, when these were currently ongoing. The biggest difference between the current research's procedure, and how 
PROBLEMS

OF MANAGEMENT IN THE $21^{\text {st }}$ CENTURY Vol. 12 , No. 1,2017

it would have been carried out if it had not been a testing of Engeströms method (e.g. 1999b), is that the steps would have entailed a new data collection (i.e. observations $\&$ interviews) and a new coding procedure at each step. The "new" data from each step would have been coded and analysed in order to provide input for the following step. If the latter had been the procedure for this research, it should have been important to be aware of the researchers' plausible influence on the ongoing activities. Something that conveys a larger responsibility as regards the researchers' role. This was a test in order to try out how AT and Engeström's method could be used for channel expansions (ibid.).

\section{Results of Research}

"The expansive visibilization of work method" was applied at findings from a prior project about channel expansion. Firstly, the findings (problems / contradictions) from the research that were found relevant are presented in compliance with step one of Engeström's (e.g. 1999b) "expansive visibilization of work method". Secondly, building upon the problems from step one, modelling of the activity systems are carried out (step two). Thirdly, in order to relate to the third step of the method, these activity systems are compared with how the interviewees from the research described their problem solutions. Finally, in this research, which primarily aims at trying out whether this method is applicable to broadening of business channels, the fourth step presents how the SMEs considered their solutions to work.

\section{Step 1 - Transition Problems That Were Causing Contradictions}

The findings from the research revealed problems (table 2) that entailed contradictions regarding the participating SME businesses latest transition respectively.

Table 2. Transition problems.

\begin{tabular}{|c|c|c|c|c|c|c|c|c|c|c|c|c|c|c|c|c|c|c|}
\hline \multirow[b]{3}{*}{ Problem area } & \multicolumn{18}{|c|}{ Company*/latest transition ${ }^{\star *}$} \\
\hline & 2 & 6 & 7 & 4 & 5 & 8 & 11 & 12 & 13 & 14 & 16 & 17 & 18 & 1 & 3 & 9 & 10 & 15 \\
\hline & $P$ & $P$ & $P$ & $E$ & $E$ & $E$ & $E$ & $E$ & $E$ & $E$ & $E$ & $E$ & $E$ & M & M & M & M & M \\
\hline Technical solutions & & & & & $x$ & $x$ & & $x$ & $x$ & $x$ & $x$ & $x$ & & & & $x$ & $x$ & $x$ \\
\hline $\begin{array}{l}\text { Lack of compe- } \\
\text { tence }\end{array}$ & & & & $x$ & $x$ & & $x$ & $x$ & $x$ & $x$ & $x$ & & $x$ & & & & $x$ & \\
\hline Money & & & & & $X$ & & & & & & & & $X$ & $x$ & & & & \\
\hline Human being & $X$ & & & $X$ & $X$ & & & & & & & & & & & & & \\
\hline $\begin{array}{l}\text { Time- and energy- } \\
\text { consuming }\end{array}$ & & & & & & $x$ & & & & & & $x$ & & & $x$ & $x$ & & \\
\hline Culture differences & & & & & & & & & & & $x$ & & & & & & & \\
\hline $\begin{array}{l}\text { Law and authori- } \\
\text { ties }\end{array}$ & & $X$ & & & & & & & & & & & & & & & & \\
\hline $\begin{array}{l}\text { Extern companies } \\
\text { delivery time }\end{array}$ & & & & & & & & & & & & & & & & $x$ & & \\
\hline Supplier & $X$ & & & & & & & & & & & & & & & & & \\
\hline Product piracy & & & & & & & & & & & & & & & $x$ & & & \\
\hline Retailers & & & & & & & & & & & $x$ & & & & & & & \\
\hline
\end{tabular}


Three companies (no. 2, 6, \& 7) transited to physical store, and did not experience the same type of problem. Hence, these three were excluded from further steps (i.e. 2 - 4) in accordance with the method. The remaining fifteen companies that transited to e-commerce or $\mathrm{m}$-commerce do reflect the same type of problem. Hence, the transitions to e- and m-commerce are seen as one (i.e. the same) type in this research. Two areas of problems were distinguished, and these were regarded as common for the remaining fifteen transitions:

- Problems connected to technical solutions (E and M): 10 out of 15, i.e. 67 percent. "It was technically a bleak at the beginning to get everything right, and we did not do everything perfect at all" (company number 10).

- Problems connected to a lack of competence (E and M): 9 out of 15, i.e. 60 percent. "We needed a lot of special skills, and collaborated with several companies" (company number 5).

Other problem categories were experienced by less than 20 percent of the fifteen SMEs, and therefore those cannot be seen as common. Hence, it is only these two problem areas that were chosen for the further steps (i.e. 2, 3, \& 4) of "the expansive visiblization of work method" (e.g. Engeström, 1999b). These two problems, or developmental tensions, are depicted in Figure 2.

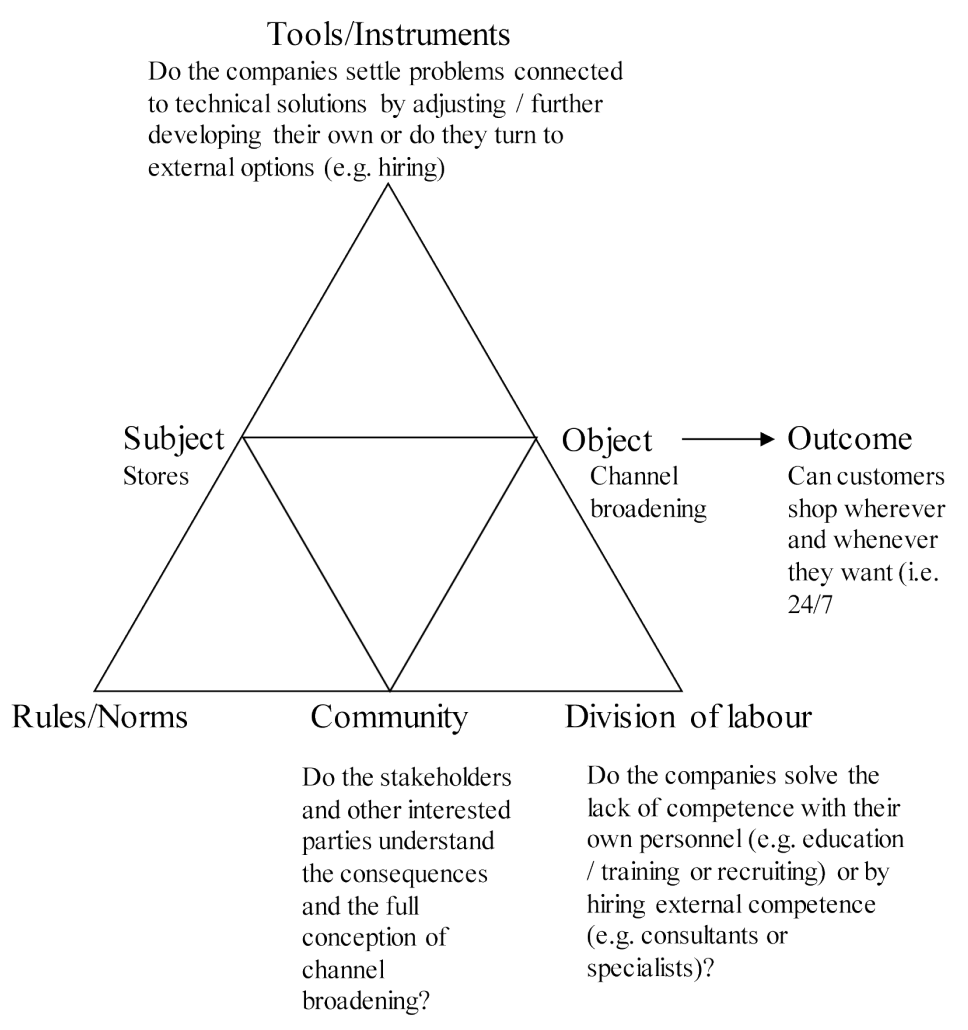

Figure 2: Developmental tensions from the project (cf. table 2).

The two main problem areas (or developmental tensions) that stood out as generalizable, from the scrutinizing of SME companies' channel broadening experiences, were related to solutions that could be categorized as two main solution opportunities: (a) handling the tensions internally, or (b) handling them externally. The problem area dealing with the technical solutions was on the one hand considered to belong to the tools' / instruments' part of the activity system and on the other hand the lack of competence was considered to belong to the division of 
PROBLEMS

OF MANAGEMENT

IN THE $21^{\text {st }}$ CENTURY

Vol. 12 , No. 1, 2017

30

labour's part, but also to the community. At least it was connected to the community when it came to issues that concerned understanding of what channel broadening actually would bring on for the businesses that were studied.

\section{Step 2 - Modelling Activity Systems}

During this testing of "the expansive visibilization of work method", the channel broadening processes were described after they actually had been carried out. However, the questions or alternatives that were available in order to solve the problem areas were described during the interviews, which provided the opportunity to work through the four steps. Since the prior ambition for this research was not to give recommendations for channel broadening, but to test if this method could be applicable, it was regarded as sufficient. From the findings the activity system was modelled as shown in Figure 3.

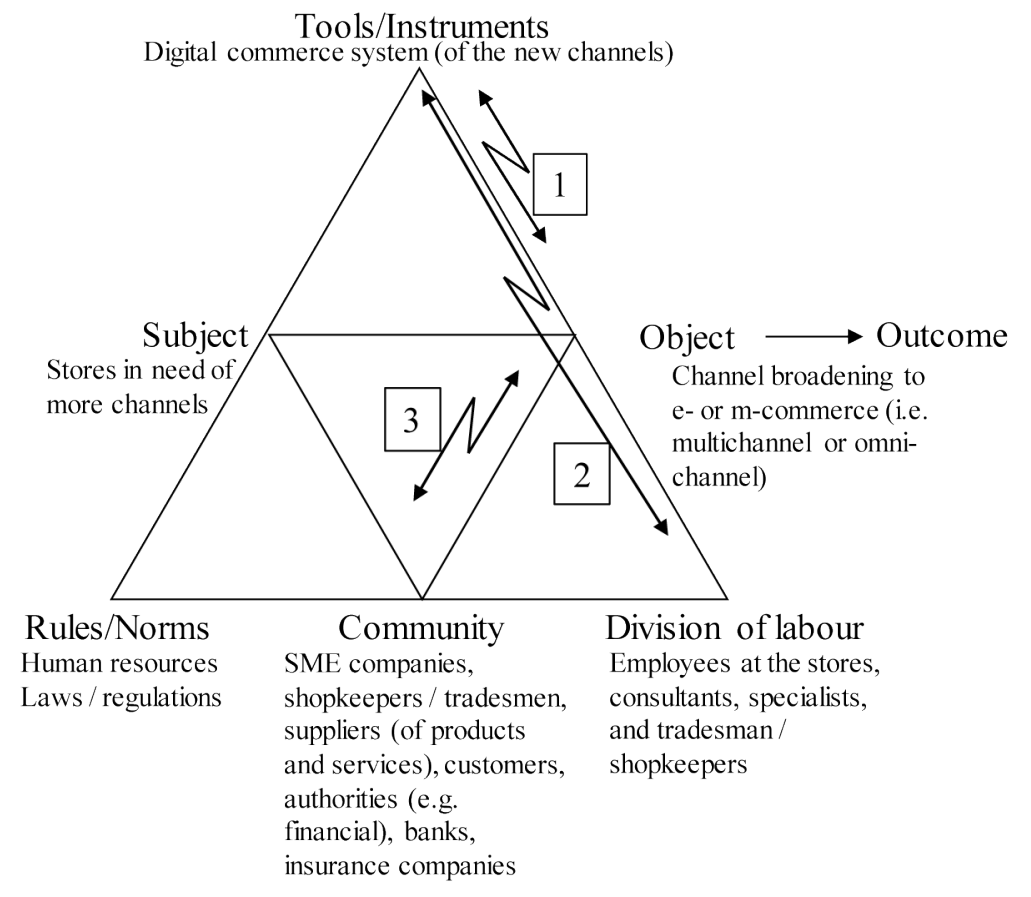

Figure 3: The activity system revealing problem areas.

In Figure 3, both contradictions are included i.e. technical problems, and a lack of competence regarding the new business channels that were added due to the channel broadening. The subject in this case is the store / stores in need of more channels (i.e. for e- / m-commerce) so the customers could shop wherever from and whenever they wanted to; the channel broadening is the object in this case with the objective to facilitate the customers shopping 24/7. It is important to keep in mind that in this case the channel broadening is actually already carried out, and the different activities, and actions are looked upon in the rear-view mirror. Consequently, it could appear as if too much has been taken for granted or has been preconceived, and therefore the importance of remembering that the findings are applied afterwards. The three contradictions that were dealt with are marked with flashes of lightning:

Contradiction number 1 is between the tools / instruments and the object, and illustrates the problems that occur when new channels and the technical solutions that are connected to those are applied. No matter if it is about creating multichannel or omni-channel. The type of 
the contradiction is primarily connected to technical solutions. "It comes down to getting a structure, and a simplicity of the web page ... there are so many models available" (company number 14).

Contradiction number 2 concerns both the tools / instruments and the division of labour and further the object is consequently included. The reason is that it would be almost impossible to exclude the object since these three are closely connected as regards the competence requirements. In other words, this contradiction is about the lack of competence that was described during the interviews. "Lack of knowledge ... is not really an obstacle, it is only an issue to solve" and "...don't be afraid to seek assistance from those who knows how" (company number 11).

Contradiction number 3 that is between the community and the object, highlights the fact that there are many interested parties and stakeholders involved in a channel broadening (as the community shows, figure 3 ) and this contradiction is primarily about a lack of competence since it is not only the technical solutions that are on the table when it comes to competence requirements. It is also to a great deal about understanding the problems (cons and pros) connected to multichannel and omni-channel as regards development in all necessary parts as well as keep them up and running. "Humans, both inside and outside the business, is the major obstacle to change and development" (company number 15).

\section{Step 3 - Designing and Implementing New Actions}

The ten companies from this research that had technical solution problems $(67 \%)$, and the nine companies that had problems with lack of competence $(60 \%)$ revealed a lot about how these problems were handled during the interviews. "Something that really hinders us in our development still belongs to the area of telephony and internet; besides, we do not have the same possibilities that they have in the city" (company number 12, located in the countryside). "We hired members of the Swedish national barista team to help us" (company number 18).

Figures 4 and 5 will focus on each problem one at the time, in order to describe the different solutions as distinctly as possible. Problems with technical solutions (i.e. tools / instruments) are marked with contradiction number 1 (as in figure 3); Figure 4 shows how this was taken care of according to the findings.

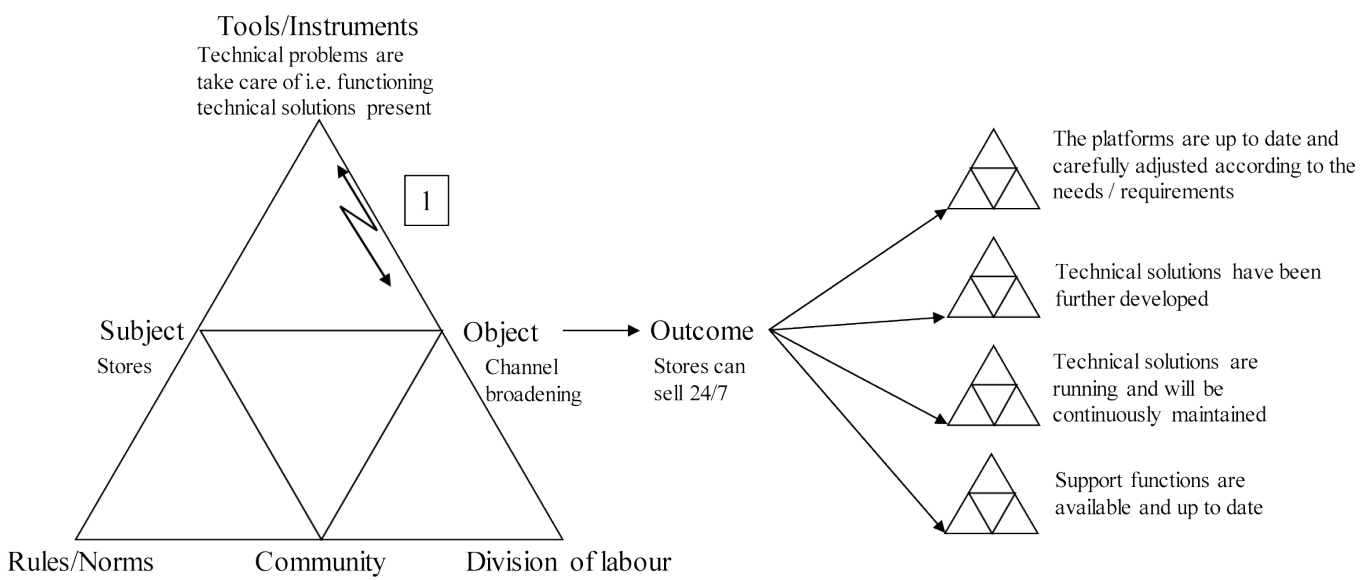

Figure 4: How the technical problems (cf. contradiction 1 in figure 3) were solved. 
PROBLEMS

OF MANAGEMENT

IN THE $21^{\text {st }}$ CENTURY Vol. 12 , No. 1,2017

It should be noticed, even though it is not obvious in Figure 4, that the solutions were of two main categories: (a) internal, and (b) external. In some cases the platforms, systems, computers, networks etc., and support functions were owned and/or maintained by the companies; they were in-house, internal equipment, and internal solutions. In some cases they were owned and/or maintained by someone else and therefore belonged to the category of outsourced, external equipment, and external solutions.

The problems that related to a lack of competence, i.e. that the personnel were unqualified of handling the systems and/or system related issues, were attended to as is shown in Figure 5.

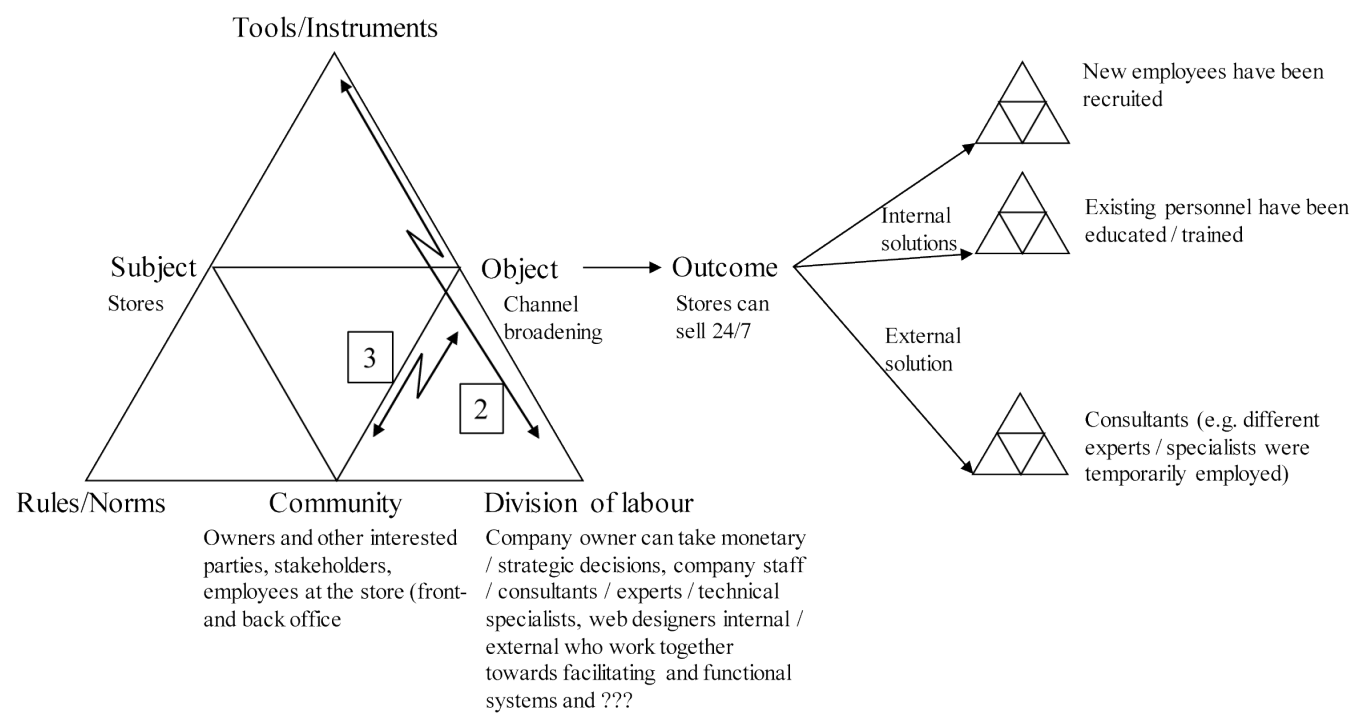

Figure 5: How the lack of competence / unqualified personnel problem (cf.
contradictions 2 and 3 in figure 3) were attended to.

As Figure 5 shows there were also in this case, i.e. regarding the lack of competence, both internal and external solutions available.

\section{Step 4 - Following and Revising}

The ten companies that had technical solution problems, and the nine companies that experienced problems, primarily solved these as Figures 4 and 5 have shown. Figure 6 shows a comprised AT structure with both problems included. 
Tools/Instruments

Technical problems are taken care of as

regards the platforms, development, support

functions, and measurements taken for

continuous working technical solutions.

Either by using external options (e.g. hiring)

or by turning to internal alternatives as

adjusting, developing, or buying new ones.

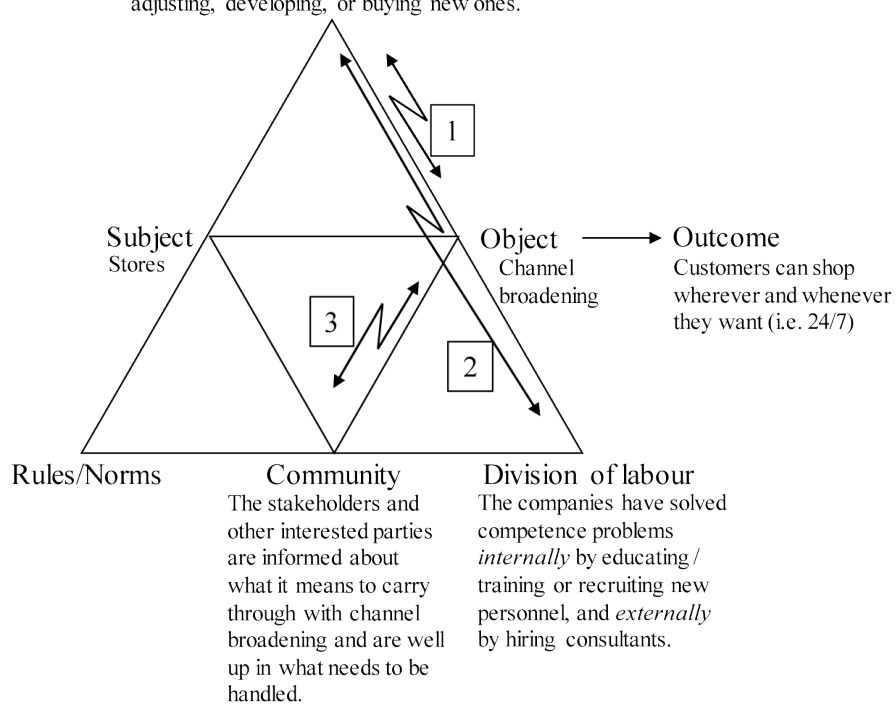

Figure 6: The AT structure after the problems from the project were solved.

Since the findings, which were used for the test of AT's applicability to channel broadening, originate from a research that now are finished it was not possible to further follow up on these solutions in terms of pros, nor regarding how revisions were needed and attended to.

\section{Discussion}

The activities from the findings that were analysed through "the expansive visibilization of work method" by Engeström (e.g. 1999b) are analysed and discussed. Further, some critique on the applied method is revealed, and proposal for further research is presented.

\section{Findings Could Gain From Being Mirrored in AT}

Change management is a delicate task to set about; people are inherently distrustful and sceptical when it comes to new job arrangements, which is quite normal though (e.g. Lewis et al., 2010). It is something that for example involves scrutinizing of one's own, employees and of co-workers competences, but also of how the organization's information systems (IS) and technology (IT) function and work. Not to forget that it is also about carrying out careful and thoroughgoing analysis of the current business model (e.g. Weill \& Vitale, 2001; Osterwalder \& Pigneur, 2010; El Sawy \& Pereira, 2013; Jeansson, Nikou, Gustavsson, Lundqvist, Marcusson, Sell, \& Walden, 2015, Jeansson et al., 2017). The latter should preferably be the starting point of a change management journey concerning channel broadening. Additionally, it could be helpful to scrutinize the actions and activities that would be involved with a BPR perspective (e.g. Hammer \& Champy, 1993). In order to get hold of the work i.e. the job tasks, that are necessary to perform, maybe in a somewhat changed form, as well as those that could rather be removed, a reengineering could be of use. However, BPR lacks the socio-spatial dimension that is possible to reach by using AT, which could provide a holistic view in which linear as well as socio-spatial, and developmental perspectives are covered. 
PROBLEMS

OF MANAGEMENT

IN THE $21^{\text {st }}$ CENTURY

Vol. 12 , No. 1, 2017

34

AT, with its triangle-shaped structure, provides various optional perspectives on activities, actions, subject, object and outcome as well as of instruments, rules, community, and division of labour that could be particularly helpful because of the opportunities to grasp the whole, and furthermore it propagates the necessity of acknowledging the history of all parts involved (Engeström \& Sannino, 2010; Engeström \& Kerosuo, 2007; Engeström, 1999a, 1999b, 2000, 2001, 2005, 2008; Fjeld et al., 2002; Foot, 2001). Engeström's (e.g. 1999b) “expansive visibilization of work method" that includes following-up on the changes, as well as taking measures to further expansive changes, were tested in prior research findings regarding SMEs that had carried out different channel broadening activities (Jeansson et al., 2015).

SMEs are particularly exposed to today's challenging demands from customers that more or less take the opportunities for shopping, without any hindrance, for granted. No matter what time it is or wherever they happen to be for the time being (Jeansson et al., 2015, 2017). Nevertheless, these demands for twenty-four-seven availability that require digital / on-line alternatives, such as electronic (e-) or mobile (m-) commerce, must be seriously taken care of in order to keep the businesses ongoing and prospering. Channel broadening is an often chosen path to move forward as a means to meet customer demands. However, prior research findings revealed many problems, or as Engeström (e.g. 1999b) expresses it contradictions, that must be attended to if the channel broadening should work as good as possible. Taking a starting point from problems / contradictions that came up during the research provided input to trying out / testing of whether "the expansive visibilization of work method" (e.g. Engeström, 1999b) would be applicable to sorting out problems connected to the customer demands on businesses.

\section{Findings and the Four Steps of "the Expansive Visibilization of Work Method"}

The four steps of the method were followed in a rear view mirror perspective since data from prior research was used in order to try out if it seemed possible to apply the method to channel broadening. This section will continue with discussing one of these at the time.

Step one

In this case, knowledge of the problems (or to use AT's vocabulary: developmental tensions) revealed during the research was applied; the transcripts from the interviews were categorized (table 2). Further, this categorization led to the first AT structure (figure 2) and the opportunity to begin sorting out the developmental tensions from different angels and perspectives. Working with AT gives the opportunity to decide which perspective, or more precisely whose perspective to start out from, i.e. decisions about the subject to begin with. In this case the stores that had carried out channel broadening were chosen as subject. In other words, their perspective was chosen for the activity analysis (cf. Engeström \& Sannino, 2010). Further, the object was the channel broadening itself and the outcome was the ability for customers to shop twenty-fourseven, because that is what the channel broadening activities aimed at (cf. Engeström, 2000, 2001). As Engeström (e.g. 1999b) states this is a work that needs to be carried out carefully in order to understand the processes, which is more or less a prerequisite for the ability to elaborate further on the AT structures. The data from the research was accurately worked through once again before starting the work with applying AT. The fundamental ambition was to gain an even better understanding of the context, history and culture as well as the work connected to the channel broadening, and the development possibilities, everything carried out with the purpose of using AT in mind. Two main contradictions were found that were connected to (a) technical solutions, and (b) a lack of competence (cf. table 2; figure 3). 
Step two

The second step involved a lot of reflection about what should be highlighted from the knowledge about the channel broadening, that in this case already was carried out, and chosen for completion of the AT structure. Now the contradictions or disturbances should be marked in the structures, and further reflected on. Hence, technical (no. 1) and competence (no. 2 and 3) contradictions / disturbances are both depicted in the AT triangle (figure 3). Even though Engeström (1999b) points out that models sometimes could be of such a general type that they are not adequate and precise enough to help recognize the basic fundaments for the specific problem. Since this research is a test of whether the AT model seems to be of any use for analysis of future channel broadening activities it was not a basic objective here to avoid being too general.

Step three

The third step aims at designing and implementing new actions; in this test however, these procedures were replaced with the research findings from the prior research about channel broadening. Which is to say, that in this case the solutions were already implemented in the stores that participated in that research. Hence, it was regarded as possible to skip the process of comparing and contrasting the former way of doing things with new / redesigned suggestions for the activities and processes e.g. in a linear form (cf. Engeström, 1999b, p. 79). In future tests, that should be carried out during ongoing channel broadening, this step will require a lot of work that involves discussions with the people involved in order to really understand the processes, and to take all three dimensions under consideration (i.e. linear, socio-spatial, and developmental). In this case such work had been carried out during the research, and it was only the documentation (transcripts) from that research that was used.

Step four

The last step of the method, yet the step that usually has to be done over and over again in order to refine and continually follow-up on, aiming at redesigning the activities / processes so the expansiveness of the reorganization would be fully acknowledged. It is inherent in this fourth step to detect new dilemmas and problems that must be carefully analysed. This is something that mostly goes on in the 'zone of proximal development' that in a way tie together the history, the present, the expanded future activities in a movement that goes back and forth (cf. figure 3, p. 69 in Engeström, 1999b). The contradictions, and the solutions that were applied, were however not possible to follow-up on since the research was already finished. Still, the test of the method indicated that this step should have been possible to work out during a real scenario and an ongoing channel broadening.

\section{Method Critique}

It should be noted that this is a test based on data from prior research in which the channel broadenings were already finished. The test was carried out in order to study if it would be possible to use AT and if so, if it would be possible in a way that could provide future channel broadening activities with useful input. Therefore the work method should be put to further tests, at ongoing channel broadening activities before any far-reaching conclusions and generalizations are possible to attain. Engeström (2008) warns for taking short-cuts in attempts of enriching AT; that is yet another reason for further following-up on these early findings. 
PROBLEMS

OF MANAGEMENT

IN THE $21^{\text {st }}$ CENTURY

Vol. 12 , No. 1,2017

36

\section{Proposal for Further Research}

As mentioned in the method critique, further research would be necessary in order to apply the method to an ongoing channel broadening; and to apply the latest methods, i.e. change laboratory, as the channel broadening is carried out in real time. Even though the findings indicate that it could be possible, still more testing must be done, at least before more detailed suggestions for applying this method at channel broadening activities could be recommended. Additionally, further testing of the method might also include generalizable categorizing of contradiction areas as well as problem solving recommendations for channel broadening.

\section{Conclusions}

An issue that should be clearly outspoken is that this research has not aimed at solving the problems that were found to be common according to the SMEs from the prior research. Instead, the focus has been on testing how the AT conception could be used for business channel broadening. More specifically it should answer the research question: How can businesses, that are about to engage in channel broadening activities, gain from applying AT, and particularly "the expansive visibilization of work method"?

The brief answer is that the testing of this method is promising and indicates that it is likely to be an accessible way of getting hold of potential problems by using this systematic method, at least in order to elucidate contradictions in a way that clarifies their origins. Hence, they would become possible to understand more precisely, and to solve them accordingly. SME businesses would most likely gain from applying AT method, i.e. change laboratory, at ongoing channel broadening cases as a means for better control and bigger opportunities of successful outcomes.

\section{Acknowledgements}

The authors gratefully acknowledge the financial support for the research from Peter Wallenberg Foundation, Sweden. Further, the authors would like to thank the research colleagues from the e-Transit project: Professor Rune Gustavsson, KTH, Royal Institute of Technology, Sweden, Pirkko Walden, Anna Sell and Shahrokh Nikou from Åbo Akademi University, Finland. Additionally, the authors are thankful for the interviewees' (from the companies that had carried out channel expansions) time and commitment.

\section{References}

Allen, D., Karanasios, S., \& Slavova, M. (2011). Working with activity theory: Context, technology, and information behavior. Journal of the American Society for Information Science and Technology, 62 (4), 776-778. doi: 10.1002/asi.21441.

El Sawy, O. A., \& Pereira, F. (2013). Business modelling in the dynamic digital space, an ecosystem approach. New York: Springer.

Engeström, Y. (1999a). Learning by expanding: Ten years after. Introduction to the German edition of Learning by Expanding, published in 1999 under the titel Lernen durch Expansion (MarburgL BdWi-Verlag). Retrieved from: http://Ichc.ucsd.edu/mca/Paper/Engeström/expanding/intro.htm (Accessed: 29-09-2016).

Engeström, Y. (1999b). Expansive visibilization of work: An activity-theoretical perspective. Computer Supported Cooperative Work, 8 (1), 63-93. doi: 10.1023/A:1008648532192.

Engeström, Y. (2000). Activity theory as a framework for analysing and redesigning work. Ergonomics, 43 (7), 960-974. doi: 10.1080/001401300409143.

Engeström, Y. (2001). Expansive learning at work: Toward an activity theoretical reconceptualization. Journal of Education and Work, 14 (1), 133-156. doi: 10.1080/13639080020028747. 
Engeström, Y. (2005). Developmental work research - Expanding activity theory in practice, ICHS (International Cultural-historical Human Science). Berlin: Lehmanns Media.

Engeström, Y., \& Kerosuo, H. (2007). From workplace learning to inter-organizational learning and back: The contribution of activity theory. Journal of Workplace Learning, 19 (6), 336-342. doi: 10.1108/13665620710777084.

Engeström, Y. (2008). Enriching activity theory without shortcuts. Interacting with Computers, 20 (2), 256-259. doi: 10.1016/j.intcom.2007.07.003.

Engeström, Y., \& Sannino, A. (2010). Studies of expansive learning: Foundations, findings and future challenges. Educational Research Review, 5 (1), 1- 24. doi: 10.1016/j.edurev.2009.12.002.

Engeström, Y., \& Scaratti, G. (2016). Editorial. Journal of Workplace Learning, 28 (4), 170-173. doi: 10.1108/JWL-03-2016-0018.

European Commission (2016). What is an SME? GROWTH Internal market, Industry, Entrepeneurship and SMEs. Retrieved from: http://ec.europa.eu/growth/smes/business-friendly-environment/smedefinition/index_en.htm (Accessed 22-03-2016).

Fjeld, M., Lauche, K., Bichsel, M.,Voorhorst, F., Krueger, H., \& Rauterberg, M. (2002). Physical and virtual tools: Activity theory applied to the design of groupware. Computer Supported Cooperative Work, 11, 153-180. doi: 10.1023/A:1015269228596.

Foot, K. A. (2001). Cultural-historical activity theory as practical theory: Illuminating the development of a conflict monitoring network. Communication Theory, 11 (1), 56-83. doi: 10.1111/j.14682885.2001.tb00233.x.

Fujitsu (2016). Walking the digital tightrope - a Fujitsu report. January 2016. Retrieved from: https://sp.ts. fujitsu.com/dmsp/Publications/public/br-fujitsu-digital-tightrope-report-em-en.pdf (Accessed 1110-2016).

Hammer, M., \& Champy, J. (1993). Reengineering the corporation. New York: Harper Business.

Jeansson, J., Nikou, S., Gustavsson, R., Lundqvist, S., Marcusson, L., Sell, A., \& Walden, P. (2015). Understanding online channel expansion in a SME context: A business model perspective, $28^{\text {th }}$ Bled eConference. Slovenia.

Jeansson, J., Nikou, S., Lundqvist, S., Marcusson, L., Sell, A., \& Walden, P. (2017). SMEs' online channel expansion: Value creating activities. Electronic Markets, 27 (1), 49-66. doi: 10.1007/s12525-0160234-1.

Karanasios, S., Allen, D., \& Finnegan, P. (2015). Information Systems Journal special issue on: Activity Theory in information systems research. Information Systems Journal, 25 (3), 309-313. doi: $0.1111 /$ isj. 12061 .

Lewis, E., Romanaggi, D., \& Chapple, A. (2010). Successfully managing change during uncertain times. Strategic HR Review, 9 (2), 12-18. doi: 10.1108/14754391011022217.

Merriam, S. B. (2009). Qualitative research, a guide to design and implementation. San Francisco: Jossey-Bass.

Mironenko, I. A. (2013). Concerning interpretations of Activity Theory. Integrated Psychological Behaviour, 47, 376-393.

Müller, P. (2016). Framtidsutsikter [Future prospects]. Svensk e-handel - DIBS årliga rapport om e-handel. DIBS by nets. Retrieved from: http://info.dibs.se/svenskehandel2016 (Accessed 16-092016).

Osterwalder, A., \& Pigneur, Y. (2010). Business model generation, Hoboken. New Jersey: John Wiley and Sons.

Patton, M. Q. (2001). Qualitative research \& evaluation methods (3 Ed.). Thousand Oaks: Sage Publications.

Rückriem, G. (2010). Digital technology, mediation, and activity theory. Cultural-Historical Psychology, 4, 30-38.

Sannino, A., Engeström, Y., \& Lahikainen, J. (2013). The dialectics of authoring expansive learning: Tracing the long tail of change laboratory. Journal of Workplace Learning, 28 (4), 245-262. doi:10.1108/JWL-01-2016-0003.

Uden, L., \& Willis, N. (2001). Designing user interfaces using Activity Theory. Proceedings of the $34^{\text {th }}$ Hawaii International Conference on System Sciences 2001.

Weill, P., \& Vitale, M. (2002). Place to space, migrating to e-business models. Boston: Harvard Business School Press.

Virkkunen, J., \& Newnham, D. (2013). The change laboratory: A tool for collaborative development of work and education. Rotterdam: Sense Publishers. 
Siw LUNDQVIST, Leif MARCUSSON, John JEANSSON. Activity theory applied at channel expansions in small and medium enterprises

PROBLEMS

OF MANAGEMENT

IN THE $21^{\text {st }}$ CENTURY

Vol. 12, No. 1, 2017

38
Received: May 23, 2017

\begin{tabular}{|ll|}
\hline Siw Lundqvist & $\begin{array}{l}\text { PhD, Assistant Professor, School of Business and Economics, Linnaeus } \\
\text { University, Gröndalsvägen 19, SE-39182 Kalmar, Sweden. } \\
\text { E-mail: siw.lundqvist@lnu.se }\end{array}$ \\
\hline Leif Marcusson & $\begin{array}{l}\text { PhD, Assistant Professor, School of Business and Economics, Linnaeus } \\
\text { University, Kalmar, Sweden. } \\
\text { E-mail: leif.marcusson@lnu.se }\end{array}$ \\
\hline John Jeansson & $\begin{array}{l}\text { PhD, Assistant Professor, School of Business and Economics, Linnaeus } \\
\text { University, Kalmar, Sweden. } \\
\text { E-mail: john.jeansson@lnu.se }\end{array}$
\end{tabular}

